\title{
Conhecimentos sobre ensino de Matemática e formação de professores produzidos em pesquisas no contexto do GPEFCom
}

\author{
Maria do Carmo de Sousa
}

\begin{abstract}
Resumo: Este artigo, decorrente de estudo qualitativo, documental e fundamentado na teoria históricocultural, tem como objetivo apresentar conhecimentos produzidos pelos integrantes do GPEFCom sobre ensino de Matemática e formação de professores. Os dados foram obtidos e analisados a partir de teses e dissertações elaboradas pelos participantes do Grupo. Priorizaram-se as pesquisas que contêm situações desencadeadoras de aprendizagem, fundamentadas na perspectiva da Atividade Orientadora de Ensino. Os resultados indicam que os conhecimentos dos professores da Educação Básica sobre as duas temáticas podem ser sistematizados e teorizados por eles mesmos quando estão inseridos em uma comunidade investigativa que prioriza o desenvolvimento de atividades de pesquisa. Mostram um modo particular de organização do trabalho coletivo, cujas diferentes perspectivas se voltam para a compreensão e a transformação de práticas educacionais.
\end{abstract}

Palavras-chave: Teoria Histórico-Cultural. Atividade Orientadora de Ensino. Situações desencadeadoras de aprendizagem. Atividade de pesquisa. Comunidade investigativa.

\section{Knowledge about teaching mathematics and formation of teachers, produced in research in the context of GPEFCom}

\begin{abstract}
This article, resulting from a qualitative, documentary study and based on historical-cultural theory, aims to present knowledge about teaching mathematics and formation of teachers produced by GPEFCom members. The data were obtained and analyzed from theses and dissertations prepared by the Group participants. Priority was given to surveys containing situations triggers of learning, based on the perspective of the Guiding Activity in Teaching. The results indicate that the knowledge of Basic Education teachers about the two themes they can be systematized and theorized by themselves when they are inserted in an investigative community that prioritizes the development of research activities. They show a particular way of organizing collective work, whose different perspectives turn to the understanding and transformation of educational practices.
\end{abstract}

Keywords: Historical-cultural theory. Teaching Guidance Activity. Triggering situations of learning. Research activity. Investigative community.

\section{Conocimiento sobre la enseñanza de las matemáticas y la formación del profesorado, producido en investigación en el contexto de GPEFCom}

Resumen: Este artículo, resultado de un estudio cualitativo, documental y basado en la teoría histórico-

Maria do Carmo de Sousa Doutora em Educação. Professora do Programa de Pós-Graduação em Educação da Universidade Federal de São Carlos (UFSCar), campus São Carlos. São Paulo, Brasil. https://orcid.org/0000-0002-5523-757X $\triangle$ mdcsousa@ufscar.br

Recebido em 28/04/2020 Aceito em 22/09/2020

Publicado em 14/10/2020 cultural, tiene como objetivo presentar conocimientos sobre la enseñanza de las Matemáticas y la formación de profesores producidos por miembros de GPEFCom. Los datos fueron obtenidos y analizados a partir de tesis y disertaciones elaboradas por los participantes del Grupo. Se dio prioridad a la investigación que contenga situaciones que desencadenan el aprendizaje, desde la perspectiva de la Actividad Orientadora de la Enseñanza. Los resultados indican que los conocimientos de los docentes de Educación Básica sobre los dos temas pueden ser sistematizados y teorizados por sí mismos cuando se insertan en una comunidad investigadora que prioriza el desarrollo de actividades de investigación. Muestran una forma particular de organizar el trabajo colectivo, cuyas diferentes perspectivas giran hacia la comprensión y transformación de las 
prácticas educativas.

Palabras clave: Teoría Histórico-Cultural. Actividad Orientadora de la Enseñanza. Situaciones desencadenantes de aprendizaje. Actividad investigadora. Comunidad investigadora.

\section{Introdução}

Ao tratarmos do conhecimento dos professores da Educação Básica sobre o ensino de Matemática que ministram e sobre a sua própria formação, não há como deixar de considerar que, aqui no Brasil, essa temática passou a ter relevância nos últimos anos, mais precisamente, a partir da criação de grupos de estudos e pesquisas que priorizam a participação desses profissionais.

Isto significa que, ao analisarmos as políticas de formação de professores, poderemos inferir que em alguns estados ainda está centrada na ideia de que os professores da Educação Básica são incapazes de pensar e, consequentemente, de produzir conhecimentos sobre os processos de ensino e de aprendizagem que ocorrem nas salas de aulas, bem como sobre a formação de professores.

Nesse contexto, é muito comum, ainda nos dias atuais, os professores da Educação Básica que já lecionam serem surpreendidos com ações, muitas vezes impositivas, que ignoram seus conhecimentos, no que diz respeito: à forma como crianças e jovens aprendem; ao currículo; aos materiais didáticos que podem auxiliar no ensino; à elaboração de produtos educacionais feitos por eles etc. Há grandes preocupações, tanto das universidades, quanto dos órgãos públicos, única e exclusivamente com o conteúdo científico a ser ensinado. Logo, os professores da Educação Básica, quando inseridos em programas de formação continuada, são incentivados a conhecer, cada vez mais, os conteúdos de suas respectivas áreas de conhecimento, para que possam ensinar mais e melhor. Ou seja, em alguns lugares, em cursos de formação, os professores da Educação Básica quase não têm oportunidade de responder perguntas que dizem respeito a quais conhecimentos estão produzindo sobre o ensino que ministram e sobre a formação de professores.

No caso específico da Matemática, há cursos de formação continuada que tem como objetivo indicar que o conhecimento dos professores da Educação Básica está relacionado aos conteúdos matemáticos que ministram. Dessa forma, quanto mais Matemática os professores conhecerem, melhor e mais efetivo será o ensino dos conteúdos matemáticos e, como consequência, os alunos da Educação Básica aprenderão e conhecerão mais Matemática. Em suma, para ensinar bem os conteúdos, basta conhecer os conceitos matemáticos.

Entretanto, apesar de algumas secretarias de educação e o governo federal investirem 
grandes cifras nesse tipo de formação continuada, que prioriza apenas os conceitos matemáticos e não o ensino de Matemática, no documento Estatísticas dos professores do Brasil, elaborado pelo Instituto Nacional de Estudos e Pesquisas Educacionais Anísio Teixeira (INEP), em 2003, encontra-se a seguinte afirmação: "os cursos de formação continuada [...], aparentemente apresentam pouco impacto no desempenho dos alunos, e isto significa que mudanças sensíveis devem ser feitas nesta área, pois, [...] boa parte dos professores participa desses cursos" (BRASIL, 2003, p. 39-40).

Entendemos que, para haver mudanças sensíveis na formação continuada de professores e, consequentemente, no ensino das diversas áreas de conhecimento, mais do que investir em cursos de curta duração, é importante criar políticas públicas que invistam na pessoa do professor, desde a graduação, de forma que ele possa desenvolver atividades de pesquisa que possibilitem configurar suas preocupações em perguntas de pesquisa e conduzir suas práticas de sala de aula; que 0 auxiliem a planejar suas ações e a selecionar os materiais didáticos e as metodologias de ensino mais apropriadas para as suas salas de aula.

A partir desses pressupostos, concordamos com Cochran-Smith e Lytle (2002, p. 79), ao considerarem que as pesquisas de professores podem nos auxiliar a construir "uma teoria diferente do conhecimento para o ensino", uma vez que as pesquisas dos professores podem ser entendidas "como uma forma diferencial e importante de conhecimento sobre o ensino". As autoras afirmam ainda que "a pesquisa feita pelos professores é uma forma de construir conhecimento tanto local quanto público; para os professores individuais; para as comunidades de professores; para os pesquisadores universitários; os formadores de professores; os políticos e os administradores da Educação" (COCHRAN-SMITH e LYTLE, 2002, p.102).

Nesse contexto, "a pesquisa dos professores" é entendida como "uma forma de conhecimento" (COCHRAN-SMITH e LYTLE, 2002, p. 77), pois as autoras defendem ainda que

\footnotetext{
essencialmente, os professores e os estudantes negociam o que vale como conhecimento na aula, quem tem esse conhecimento e como pode ser gerado, organizado e valorizado. 0 que estamos defendendo aqui é que através da pesquisa, os professores podem chegar a entender como isso se sucede em suas próprias aulas e como se configuram suas próprias interpretações dos acontecimentos didáticos. Assumindo, então que a pesquisa dos professores é uma forma de conhecer o próprio conhecimento [...]. (p. 82)
}

Ao concordarmos com as autoras supracitadas e com as ideias centrais apresentadas até aqui, que envolvem o conhecimento dos professores sobre o ensino que ministram, mobilizamonos, a criar o Grupo de Pesquisa Formação Compartilhada de Professores - Escola e 
Universidade (GPEFCom), na Universidade Federal de São Carlos (UFSCar), considerando-se que os integrantes, em sua maioria, são professores da Educação Básica e, por esse motivo, lecionam nas várias áreas de conhecimento, tanto em escolas públicas quanto privadas. Boa parte deles desenvolve pesquisas, em nível de pós-graduação, na área da Educação, no Mestrado (Profissional e Acadêmico) e no Doutorado. E, ao final do curso, muitos deles têm participado de concursos promovidos pelas universidades públicas e são aprovados. A partir daí, abandonam a Educação Básica e passam a lecionar no Ensino Superior, especialmente, em cursos de licenciaturas.

Há de se considerar ainda que as pesquisas desses professores podem ser consideradas sistemáticas e intencionais, conforme apontam os estudos de Cochran-Smith e Lytle (2002), pois consideram não apenas a dinâmica fluente das aulas, especialmente quando o foco está nas aulas de Matemática, como também as particularidades e singularidades das salas de aula. São intencionais porque os professores estudam, planejam ações e elaboram, de forma coletiva, produtos educacionais que pretendem intervir positivamente nos processos de ensino e aprendizagem de suas turmas. São sistemáticas porque organizam, de forma acadêmica, as intervenções que ocorrem nas aulas, dentre elas, as aulas de Matemática.

É com este objetivo - apresentar alguns conhecimentos adquiridos pelos professores da Educação Básica, integrantes do GPEFCom, sobre o ensino de Matemática e sobre a formação docente, enquanto desenvolvem pesquisas no Mestrado (Acadêmico e Profissional) e no Doutorado, na área da Educação - que escrevemos este artigo.

A questão que conduziu o estudo qualitativo, documental e fundamentado na teoria histórico-cultural foi: Quais conhecimentos sobre o ensino de Matemática e a formação de professores estão explicitados nas pesquisas de professores de Matemática da Educação Básica, integrantes do GPEFCom?

Para respondê-la, a partir da introdução, organizamos o artigo em torno dos seguintes itens: fundamentos teóricos e metodológicos do estudo; metodologia do estudo; contextualização do GPEFCom; análise das pesquisas desenvolvidas pelos professores da Educação Básica no GPEFCom; e considerações finais.

\section{Fundamentos teóricos e metodológicos}

Ao planejarmos a configuração do GPEFCom, tivemos que fazer escolhas teóricas e metodológicas, uma vez que, inicialmente, boa parte dos professores da Educação Básica, 
integrantes do grupo, desenvolviam suas pesquisas no contexto do Mestrado Profissional, conforme apresentaremos na próxima seção. Dessa forma, elaboravam os produtos educacionais, a partir de situações desencadeadoras de aprendizagem (SDA), na perspectiva da Atividade Orientadora de Ensino (AOE), segundo estudos de Moura (2001). Ou seja, tanto as pesquisas dos professores quanto os pressupostos que estamos usando neste estudo se fundamentam na teoria histórico-cultural.

Ao nos referirmos ao conceito de atividade, fazemos uso dos estudos de Davydov (1988, p. 17), uma vez que, para o autor, "as origens materialistas dialéticas do conceito psicológico de atividade" mostram que há relações diretas entre os conceitos de atividade, psique e consciência; "isto requer uma compreensão tal da consciência que responda às exigências do enfoque sobre seu caráter de atividade [...]. A consciência é a forma superior da psique e é própria só do homem".

Além da relação entre atividade, psique e consciência, o mesmo autor chama a nossa atenção para o fato de que, tanto a categoria filosófica de atividade quanto os tipos de atividade das pessoas possuem caráter histórico-social, pois "a atividade de trabalho coletiva, adequada, sensório-objetal, transformadora, das pessoas. Na atividade se põe em descoberto a universalidade do sujeito humano" (DAVYDOV, 1988, p. 27). Isto quer dizer que

\footnotetext{
a essência da atividade do homem pode ser descoberta no processo de análise do conteúdo de conceitos inter-relacionados, como trabalho, organização social, universalidade, liberdade, consciência, plano de uma finalidade, cujo portador é o sujeito genérico. Toda a atividade espiritual das pessoas está determinada pela prática social e tem uma estrutura, em princípio, afim com ela. A atividade é a substância da consciência humana. (DAVYDOV, 1988, p. 27)
}

Ao mesmo tempo, quando Davydov (1988) se refere à teoria da atividade preconizada por Leontiev, chama a atenção para um dos elementos que a compõe: a necessidade, considerandose que "a atividade do sujeito sempre está ligada a certa necessidade" (DAVYDOV, 1988, p. 28).

Nesta perspectiva, a atividade supera a concepção tanto dos denominados idealistas, quanto dos mecanicistas, "difundidas na psicologia burguesa", uma vez que a utilização da categoria atividade permite superar o "postulado do caráter imediato", típico das orientações mecanicistas (DAVYDOV, 1988, p. 29).

A partir desses pressupostos, Leontiev e seus colaboradores definiram a "estrutura psicológica da atividade". Para eles, "a atividade integral tem os seguintes componentes: necessidade $\leftrightarrow$ motivo $\leftrightarrow$ finalidade $\leftrightarrow$ condições para obter a finalidade (a unidade da finalidade das condições conforma a tarefa) e os componentes, correlacionáveis com aqueles: atividade $\leftrightarrow$ 
ação ↔ operações" (DAVYDOV, 1988, p. 31). Nesse caso, a estrutura é rígida e linear, porém, durante a realização da atividade, sua estrutura pode sofrer mudanças e transformações.

\begin{abstract}
Assim, a atividade pode perder seu motivo e transformar-se em ação: esta, se se modifica sua finalidade, pode converter-se em operação. 0 motivo de uma certa atividade pode passar a ser a finalidade da ação, com cujo resultado esta última se converte em outra atividade. Têm lugar, permanentemente, as seguintes transformações mútuas: atividade $\leftrightarrow$ ação $\leftrightarrow$ operação e motivo $\leftrightarrow$ finalidade $\leftrightarrow$ condições. (DAVYDOV, 1988, p. 32)
\end{abstract}

Mas podemos nos perguntar: 1) De que forma os pesquisadores russos introduziram 0 conceito de atividade na área da Educação?; 2) Que relações pode haver entre a atividade preconizada por Leontiev e os sistemas de ensino?; 3) No caso do Brasil e, consequentemente, nas pesquisas feitas pelos professores da Educação Básica, integrantes do GPEFCom, como 0 conceito de atividade vem sendo inserido?

Para que as ideias que aqui estamos apresentando pudessem frequentar os sistemas de ensino na Rússia, Davidov e Markova (1987) indicam, em seus estudos, o papel que a escola pode desempenhar na vida das crianças e dos jovens. Para eles, "o ingresso à escola marca 0 começo de uma nova etapa na vida da criança; nela muitas mudanças ocorrem tanto no aspecto da organização externa, quanto interna" (DAVIDOV e MARKOVA, 1987, p. 176-177). Esse novo momento, que envolve as diversas relações que ocorrem entre as próprias crianças, a família e a escola, pode ser caracterizado como atividade de estudo.

\footnotetext{
Por meio desta atividade os escolares dos primeiros anos devem assimilar a relação teórica para a realidade que permite levar em conta a lógica das propriedades e leis objetivas dessa realidade. Sobre a base desta vinculação as crianças podem assimilar os conceitos científicos iniciais da linguística, das matemáticas e de outras disciplinas escolares. Tal assimilação pressupõe o estudo, pelas crianças, das condições de origem dos correspondentes conceitos, o que, por sua vez, forma neles os sistemas de ações mentais que permitem operar adequadamente com estes conceitos (DAVIDOV e MARKOVA, 1987, p. 176-177).
}

Podemos chamar atenção para o fato de que, para que a atividade de estudo possa se formar nas crianças que estão nas escolas, "é necessário introduzir desde o primeiro ano, cursos sistemáticos de linguística, Matemática e outras disciplinas escolares. Sobre sua base resulta indispensável, desde o começo mesmo, estruturar nos alunos do primeiro ano as formas iniciais do pensamento abstrato, teórico" (DAVIDOV e MARKOVA, 1987, p. 177).

No caso específico do Brasil, Rosa, Moraes e Cedro (2010), a partir da teoria da atividade de Leontiev, denominaram a atividade de estudo de atividade de aprendizagem. Defendem que, para que as atividades de aprendizagem possam ser organizadas pelos professores da Educação 
Básica, devem ter como ponto de partida e de chegada o pensamento teórico dos estudantes, uma vez que, ao analisarmos as diferenças existentes entre o pensamento empírico e 0 pensamento teórico, não há como negar que, tanto nas escolas russas, quanto nas brasileiras,

quando observamos uma organização do ensino fundamentada nas bases do pensamento empírico, é comum encontrarmos estudantes com grande dificuldade em diferenciar os atributos essenciais dos insubstanciais de um objeto ou fenômeno. Isso ocorre porque nem sempre a exemplificação, a operacionalização ou a definição adequada de determinado conceito garantem que o estudante tenha se apropriado dos atributos essenciais do objeto ou fenômeno. Em situações que exigem somente a identificação ou em circunstâncias que requerem a resolução de problemas práticos, o conhecimento das propriedades externas pode ser suficiente. Contudo, a compreensão teórica das distinções entre os objetos ou fenômenos exige 0 entendimento das suas características substanciais, que necessariamente não precisam corresponder aos aspectos externos, e o reconhecimento da sua existência em determinados objetos ou fenômenos. (ROSA, MORAES e CEDRO, 2010, p. 7879)

Concordamos com os pesquisadores brasileiros aqui citados que há de se romper com um tipo de organização de ensino que tenha como ponto de partida e, muitas vezes, de chegada, o pensamento empírico, para que os professores da Educação Básica passem a ser desafiados no sentido "de propor uma organização do ensino que não se limite simplesmente a reforçar o desenvolvimento do pensamento empírico, posto que se trata de um tipo de pensamento pautado nos aspectos externos e observáveis dos objetos e fenômenos e, como tal, desenvolve-se independentemente da escolarização do sujeito" (ROSA, MORAES e CEDRO, 2010, p. 80).

Para que possamos, juntamente com os professores da Educação Básica, pensar em outras formas de organizar o ensino, especialmente, o ensino de Matemática, há de se pressupor que

\footnotetext{
0 ensino realizado nas escolas pelos professores deve ter a finalidade de aproximar os estudantes de um determinado conhecimento. Daí a importância de que os professores tenham compreensão sobre seu objeto de ensino, que deverá se transformar em objeto de aprendizagem para os estudantes. Além disso, é fundamental que, no processo de ensino, o objeto a ser ensinado seja compreendido pelos estudantes como objeto de aprendizagem. Para a teoria histórico-cultural, isso só é possível se esse mesmo objeto se constituir como uma necessidade para eles. Assim, os conhecimentos teóricos são ao mesmo tempo objeto e necessidade na atividade de aprendizagem. (MOURA et al., 2010, p. 92)
}

Defendemos, juntamente com os autores que a atuação dos professores brasileiros, no sentido de analisar, elaborar e desenvolver o pensamento teórico nos estudantes, a partir da atividade de aprendizagem, é de extrema importância. Os elementos que compõem o conceito de atividade — o motivo, a necessidade e as ações — devem estar em consonância e presentes em todos os momentos que pressupõem a organização do ensino. 
As ações do professor na organização do ensino devem criar, no estudante, a necessidade do conceito, fazendo coincidir os motivos da atividade com o objeto de estudo. 0 professor, como aquele que concretiza objetivos sociais objetivados no currículo escolar, organiza o ensino: define ações, elege instrumentos e avalia o processo de ensino e aprendizagem. (MOURA et al., 2010, p. 94)

Mas como organizar o ensino, a partir desses pressupostos teóricos, nas escolas que temos, especialmente quando tratamos do ensino de Matemática na Educação Básica?

Ao tentarmos responder a essa pergunta, temos que atentar para a formação dos professores, considerando-se que uma possibilidade de organização do ensino que leve em conta a "unidade entre ensino e aprendizagem", conforme apontam os pressupostos teóricos e metodológicos da teoria histórico-cultural, vem sendo defendida e denominada por Moura et al. (2010) de "Atividade Orientadora de Ensino" (AOE), a qual

mantém a estrutura de atividade proposta por Leontiev, ao indicar uma necessidade (apropriação da cultura), um motivo real (apropriação do conhecimento historicamente acumulado), objetivos (ensinar e aprender) e propor ações que considerem as condições objetivas da instituição escolar [...]. Na AOE, ambos, professor e estudante, são sujeitos em atividade e como sujeitos se constituem indivíduos portadores de conhecimentos, valores e afetividade, que estarão presentes no modo como realizarão as ações que têm por objetivo um conhecimento de qualidade nova. Tomar consciência de que sujeitos em atividade são indivíduos é primordial para considerar a AOE como um processo de aproximação constante do objeto: o conhecimento de qualidade nova. A atividade, assim, só pode ser orientadora. Nesse sentido, a AOE toma a dimensão de mediação ao se constituir como um modo de realização de ensino e de aprendizagem dos sujeitos que, ao agirem num espaço de aprendizagem, se modificam e, assim, também se constituirão em sujeitos de qualidade nova. (MOURA et al., 2010, p. 96-97)

Neste caso, a AOE tem relação direta com o pensamento teórico, pois, segundo Moura et al. (2010, p. 99), "o ensino tomado como atividade, como o concebe Leontiev - com um caráter de processo social, mediado por instrumentos e signos, e estruturado com base em uma necessidade -, exige um modo especial de organização". Tal organização pressupõe "que objetivos, ações e operações se articulam como atividade, que dá à AOE a dimensão de unidade formadora do estudante e do professor, ao concretizarem a apropriação da cultura no contexto da educação escolar" (MOURA et al., 2010, p. 99). Ao mesmo tempo, há de se considerar a intencionalidade do professor, no que diz respeito à "qualidade de mediação da AOE", considerando-se que

é primordialmente a responsável pela aprendizagem de conceitos científicos e pelo desenvolvimento do pensamento teórico, orientada pela intencionalidade de impactar os sujeitos, proporcionando as alterações no desenvolvimento de suas funções psíquicas e a apropriação de conceitos científicos. (MOURA et al., 2010, p. 99) 
Mas como mobilizar as necessidades, os motivos, os objetivos, as ações e as operações do professor e dos estudantes de que falam os autores?

Entendemos que a resposta a essa pergunta está vinculada ao que Moura et al. (2010) definem como situação desencadeadora de aprendizagem (SDA), a qual é organizada, intencionalmente, pelo professor,

tomando-se por base os seus objetivos de ensino que, como dissemos, se traduzem em conteúdos a serem apropriados pelos estudantes no espaço de aprendizagem. As ações do professor serão organizadas inicialmente visando colocar em movimento a construção da solução da situação desencadeadora de aprendizagem. Essas ações, por sua vez, ao serem desencadeadas, considerarão as condições objetivas para o desenvolvimento da atividade: as condições materiais que permitem a escolha dos recursos metodológicos, os sujeitos cognoscentes, a complexidade do conteúdo em estudo e o contexto cultural que emoldura os sujeitos e permite as interações socioafetivas no desenvolvimento das ações que visam ao objetivo da atividade - a apropriação de um certo conteúdo e do modo geral de ação da aprendizagem. (MOURA et al., 2010, p. 103)

Quando se analisa o processo de elaboração e de concretização da AOE como mediadora, "na dimensão teórica e prática, da atividade do professor e do estudante" (MOURA et al., 2010, p. 108), pode-se afirmar que tal processo desencadeia a formação tanto do estudante quanto do professor.

No caso do estudante, "ao ser sujeito da atividade na atividade de aprendizagem, se apropria do conhecimento teórico, desenvolvendo-se, transformando-se; humanizando-se, no movimento de análise e síntese inerente ao processo de solução do problema de aprendizagem da AOE" (MOURA et al., 2010, p. 108). Já, no caso do professor, há de se enfatizar que, enquanto ensina, também aprende, considerando-se que sua formação

tem por objetivo ensinar o estudante e que, entretanto, nas discussões coletivas, no movimento dos motivos de sua atividade, das ações, operações e reflexões que realiza, aprende a ser professor aproximando o sentido pessoal de suas ações da significação da atividade pedagógica como concretizadora de um objetivo social. (MOURA et al., 2010, p. 108)

A partir desses pressupostos, podemos afirmar que, do ponto de vista da teoria históricocultural, no processo de formar-se, enquanto analisa, elabora e desenvolve SDA na perspectiva da $\mathrm{AOE}$, o professor tem a oportunidade de estar em atividade, permanentemente.

Aqui, a atividade pode ser entendida como o movimento de abstrair o resultado de ações, antes mesmo de realizá-las, provocadas por necessidades reais, advindas da interação do homem com o meio pela condição de nele viver (MOURA et al., 2003). Nessa perspectiva, as necessidades 
reais dos professores advêm de suas relações com os estudantes, diariamente, nas escolas em que estão inseridos. A atividade do professor adquirirá um novo status - será considerada atividade de pesquisa - especialmente, quando ele for capaz de definir os elementos constitutivos que permeiam o pensar sobre as elaborações decorrentes da análise das AOE feitas pelos professores; ou, ainda, quando permitir a análise dos inesperados estudados por Caraça (1998), caso esses surjam durante o processo de formar-se pelo conhecimento científico.

Ou seja, estamos indicando que a atividade de pesquisa, no caso específico dos professores da Educação Básica, dentre eles, os integrantes do GPEFCom, tem relação direta com os pressupostos da $\mathrm{AOE}$, pois

\begin{abstract}
os fundamentos teórico-metodológicos da AOE, cujos pressupostos estão ancorados na teoria histórico-cultural e na teoria da atividade, são indicadores de um modo de organização do ensino para que a escola cumpra sua função principal, que é possibilitar a apropriação dos conhecimentos teóricos pelos estudantes. Assim, a AOE, como mediação, é instrumento do professor para realizar e compreender seu objeto de estudo: o processo de ensino de conceitos. Ee instrumento do estudante, que, por meio dela, pode apropriar-se de conhecimentos teóricos. Desse modo, a AOE tem as características de fundamento para o ensino e é também fonte de pesquisa sobre 0 ensino. Assim, profissionais pesquisadores podem usar sua estrutura para identificar motivos, necessidades, ações desencadeadoras e sentidos atribuídos pelos sujeitos no processo de ensino. (MOURA et al., 2010, p. 108-109)
\end{abstract}

Ou seja, não é à toa que defendemos que a atividade de pesquisa, na perspectiva da $\mathrm{AOE}$, é peça fundamental para a formação de professores, e por esse motivo concordamos com os pesquisadores que, citados por Moura et al. (2010), indicam em seus estudos que, nos últimos anos, pelo menos duas vertentes vêm se configurando, no Brasil, sobre o papel que a AOE pode desempenhar, tanto na formação do estudante quanto na formação de professores.

A primeira vertente defende a "utilização do conceito para a organização da atividade pedagógica" e a segunda considera a AOE "como instrumento metodológico de pesquisas sobre o ensino, ou seja, a AOE vem sendo explorada como fonte de pesquisa e como fundamento para o ensino" (MOURA et al., 2010, p. 99-100).

No caso das pesquisas dos professores da Educação Básica, desenvolvidas no âmbito do GPEFCom, a AOE tem se configurado como fundamento para o ensino e, por esse motivo, concordamos com Sforni (2015, p. 382), quando nos apresenta cinco princípios que podem orientar a ação dos professores, no que diz respeito à organização do ensino em sala de aula, na referida perspectiva: "1. Princípio do ensino que desenvolve; 2. Princípio do caráter ativo da aprendizagem; 3. Princípio do caráter consciente; 4. Princípio da unidade entre o plano material (ou materializado) e o verbal; 5. Princípio da ação mediada pelo conceito". Entendemos que estes 
princípios se aproximam daqueles elaborados por Davydov (1988).

O Quadro 1 representa uma síntese do quadro elaborado por Sforni (2015, p. 393), e sinaliza tanto os princípios apresentados quanto as ações docentes relacionadas a cada um deles.

Quadro 1: Princípios didáticos e ações docentes na perspectiva da AOE

\begin{tabular}{|c|c|c|}
\hline Princípios didáticos & Caracterização & Ações docentes \\
\hline $\begin{array}{l}\text { 1. Do Ensino que } \\
\text { desenvolve }\end{array}$ & $\begin{array}{l}\text { Esse princípio indica que orientar-se pelo } \\
\text { princípio do ensino desenvolvimental } \\
\text { implica que, ao planejar, executar e } \\
\text { avaliar o ensino, o norte deve ser o } \\
\text { próximo desenvolvimento dos } \\
\text { estudantes. }\end{array}$ & $\begin{array}{l}\text { a) avaliação do nível de desenvolvimento } \\
\text { atual e previsão do nível de } \\
\text { desenvolvimento esperado; } \\
\text { b) uso de atividades com os conceitos } \\
\text { que mobilizam as Funções Psíquicas } \\
\text { Superiores; } \\
\text { c) criação de situações em que os } \\
\text { estudantes expressem verbalmente o } \\
\text { que e como estão pensando (como estão } \\
\text { atuando mentalmente com os conceitos). }\end{array}$ \\
\hline $\begin{array}{l}\text { 2. Do Caráter Ativo da } \\
\text { Aprendizagem }\end{array}$ & $\begin{array}{l}\text { Esse princípio tem por base a } \\
\text { compreensão de que, mediante o ensino, } \\
\text { desenvolvem-se, conjuntamente, forma } \\
\text { e conteúdo do pensamento. Não se trata } \\
\text { de uma acumulação dos conhecimentos } \\
\text { já em sua síntese, em sua definição } \\
\text { verbal ou "[...] cobertura verbal", como } \\
\text { nomeia Davidov (1987, p. 148), mas sim } \\
\text { de uma apropriação do processo lógico- } \\
\text { histórico de elaboração do conceito e, ao } \\
\text { mesmo tempo, do desenvolvimento } \\
\text { conjunto de formas de pensamento mais } \\
\text { complexas. }\end{array}$ & $\begin{array}{l}\text { a) elaboração de situações problema que } \\
\text { permitam inserir o estudante no horizonte } \\
\text { investigativo que deu origem ao conceito; } \\
\text { b) previsão de momentos em que os } \\
\text { alunos dialoguem entre si e elaborem } \\
\text { sínteses coletivas, mesmo que sejam } \\
\text { provisórias; } \\
\text { c) orientação do processo de elaboração } \\
\text { de sínteses conceituais pelos } \\
\text { estudantes. }\end{array}$ \\
\hline $\begin{array}{l}\text { 3. Do Caráter } \\
\text { Consciente }\end{array}$ & $\begin{array}{l}\text { Esse princípio indica que [...] é a } \\
\text { consciência do conteúdo central da } \\
\text { atividade e das razões de suas ações } \\
\text { que leva o aluno a reconhecer nas ações } \\
\text { realizadas um modo geral de ação e a } \\
\text { generalizar o conhecimento, não se } \\
\text { restringindo ao modelo da atividade } \\
\text { oferecida. Ou seja, não basta que o } \\
\text { conteúdo esteja contido na atividade, } \\
\text { tampouco basta a ação do aluno: é } \\
\text { preciso que este tome consciência da } \\
\text { relação da sua ação com o conteúdo da } \\
\text { atividade. Nesse sentido, é necessário } \\
\text { que o professor também tenha } \\
\text { consciência do conteúdo central da } \\
\text { atividade para que, assim, possa prever } \\
\text { ações que dirijam a atenção dos } \\
\text { estudantes para o objeto da } \\
\text { aprendizagem. As interações verbais } \\
\text { entre professor e estudantes favorecem } \\
\text { o acompanhamento do tipo de relação } \\
\text { que o aluno está estabelecendo com o } \\
\text { conteúdo: se está preso a situações } \\
\text { particulares ou periféricas ou se está }\end{array}$ & $\begin{array}{l}\text { a) elaboração de atividades que tenham } \\
\text { potencial para promover } \\
\text { o modo de ação geral com o conceito; } \\
\text { b) previsão de ações mentais para que o } \\
\text { conteúdo central da atividade seja o foco } \\
\text { da consciência dos estudantes; } \\
\text { c) atenção para as explicitações verbais } \\
\text { dos estudantes, as quais sinalizam se } \\
\text { eles estão estabelecendo relação entre o } \\
\text { particular e o geral. }\end{array}$ \\
\hline
\end{tabular}




\begin{tabular}{|c|c|c|}
\hline & $\begin{array}{l}\text { voltado para o que é nuclear na atividade } \\
\text { proposta. }\end{array}$ & \\
\hline $\begin{array}{l}\text { 4. Da Unidade entre o } \\
\text { Plano Material (ou } \\
\text { Materializado) e o } \\
\text { Verbal }\end{array}$ & $\begin{array}{l}\text { A necessidade de criação de situações } \\
\text { problema que sejam desencadeadoras } \\
\text { da aprendizagem e a necessidade de } \\
\text { ascensão do abstrato ao concreto } \\
\text { implicam a necessidade de interação } \\
\text { entre o plano material (fenômenos ou } \\
\text { objetos), ou representações dele } \\
\text { (ilustrações, mapas, filmes, maquetes, } \\
\text { etc.), e o plano mental (atuação com as } \\
\text { abstrações). No movimento } \\
\text { abstrato//concreto e concreto/abstrato, a } \\
\text { mediação da linguagem verbal (oral e } \\
\text { escrita) é fundamental, já que pode } \\
\text { tornar os processos conscientes, } \\
\text { destacar o que é essencial da atividade } \\
\text { realizada e focar o(s) conceito(s) nela } \\
\text { contido(s). }\end{array}$ & $\begin{array}{l}\text { a) organização de atividades que } \\
\text { coloquem em interação o plano material } \\
\text { ou materializado (ilustrativo) e a } \\
\text { linguagem verbal (oral e escrita); } \\
\text { b) uso de textos científicos e clássicos da } \\
\text { respectiva área de conhecimento. }\end{array}$ \\
\hline $\begin{array}{l}\text { 5. Da Ação Mediada } \\
\text { pelo Conceito }\end{array}$ & $\begin{array}{l}\text { Neste princípio há a indicação de que, se } \\
\text { os conceitos científicos são mediadores } \\
\text { sociais na interação do sujeito com os } \\
\text { fenômenos, a apropriação desses } \\
\text { mediadores significa a possibilidade de } \\
\text { tê-los como instrumento simbólico que } \\
\text { orientam as ações mentais (LEONTIEV, } \\
\text { 1978). Nesse sentido, no planejamento } \\
\text { de ensino cabe prever a contextualização } \\
\text { do conceito, não apenas em termos de } \\
\text { sua presença na realidade imediata, mas } \\
\text { também em termos de seu movimento } \\
\text { lógico-histórico de elaboração. }\end{array}$ & $\begin{array}{l}\text { a) análise da gênese do conceito no seu } \\
\text { aspecto lógico-histórico } \\
\text { para buscar o que é nuclear no conceito; } \\
\text { b) elaboração de problemas } \\
\text { desencadeadores com a finalidade de } \\
\text { levar os alunos a resolvê-los por meio da } \\
\text { mediação do conceito; } \\
\text { c) inclusão de novos problemas de } \\
\text { aprendizagem ao final do processo de } \\
\text { estudo para analisar se os alunos } \\
\text { operam mentalmente com o conceito. }\end{array}$ \\
\hline
\end{tabular}

Fonte: Sforni (2015, p. 385-393).

A partir dos princípios apresentados no Quadro 1, que consideram os pressupostos teóricos dos conceitos de atividade, atividade de aprendizagem, AOE e SDA, há de se considerar ainda que, quando tratamos da pesquisa dos professores que lecionam, especialmente, nas escolas da Educação Básica, segundo Diniz-Pereira e Zeichner (2011, p. 11), "diferentes termos são usados na literatura específica para se referir à pesquisa feita por educadores a partir de sua própria prática na escola e/ou em sala de aula. Os mais comuns são: pesquisa-ação, investigação na ação, pesquisa colaborativa e pesquisa emancipatória". Cada um desses termos, cunhados por autores como Lewin, Carr e Kemmis, dentre outros, traz consigo uma definição do termo "pesquisa".

No entanto, foram Cochran-Smith e Lytle que "tentaram sistematizar e descrever o que poderia ser uma tipologia de trabalho de investigação destes profissionais" (FIORENTINI e LORENZATO, 2006, p. 73). Para elas, a pesquisa dos professores pode ser definida como: 
um estudo sistemático e intencionado dos professores sobre seu próprio trabalho na sala de aula e na escola. [...] Com sistemático nos referimos fundamentalmente às formas ordenadas de reunir e registrar informações, documentar as experiências que acontecem dentro ou fora da escola e criar uma espécie de registro escrito. [...] Com intencionado indicamos que a investigação dos professores é uma atividade planejada, isto é, não espontânea. (COCHRAN-SMITH e LYTLE, 1999 apud FIORENTINI e LORENZATO, 2006, p. 73)

Faz-se necessário enfatizar ainda que as autoras supracitadas "há mais de três décadas rejeitam o pressuposto de que o conhecimento da prática pedagógica é gerado de 'fora para dentro', isto é, por pesquisadores universitários distanciados das práticas escolares" (FIORENTINI e CRECCI, 2016, p. 507). Dessa forma, "a partir dessa perspectiva, identificam três diferentes concepções de aprendizagem docente, tendo como base os diferentes entendimentos e relações que se estabelecem entre conhecimento e prática profissional" (FIORENTINI e CRECCI, 2016, p. 511), conforme mostra o Quadro 2.

Quadro 2: concepções de aprendizagem docente

\begin{tabular}{|c|c|c|}
\hline Conhecimento-para-prática & Conhecimento-na-prática & Conhecimento-da-prática \\
\hline $\begin{array}{l}\text { Parte do pressuposto de que os } \\
\text { acadêmicos e especialistas geram } \\
\text { os conhecimentos formais e teorias } \\
\text { para que os professores os } \\
\text { aprendam para utilizar ou aplicar na } \\
\text { prática. Essa concepção supõe que } \\
\text { o conhecimento formal serve para } \\
\text { organizar e aprimorar a prática } \\
\text { profissional do professor. Valendo- } \\
\text { se desse pressuposto, conhecer } \\
\text { mais (conteúdos, estratégias, } \\
\text { teorias educacionais etc.) e aplicar } \\
\text { esses conhecimentos ajuda o } \\
\text { professor a melhorar sua prática } \\
\text { docente. Nesse cenário, os } \\
\text { espaços de aprendizagem } \\
\text { profissional são geralmente cursos, } \\
\text { oficinas e workshops conduzidos } \\
\text { por especialistas da universidade. } \\
\text { Essa concepção, portanto, segue o } \\
\text { modelo da racionalidade técnica, } \\
\text { pois, conforme Schön, (apud } \\
\text { Cochran-Smith e Lytle, 1999, p. } \\
\text { 263), "presume que os profissionais } \\
\text { são solucionadores de problemas e } \\
\text { que os problemas da prática } \\
\text { profissional [...] podem ser } \\
\text { resolvidos instrumentalmente } \\
\text { através da aplicação de teorias e } \\
\text { técnicas embasadas na pesquisa } \\
\text { acadêmica" }\end{array}$ & $\begin{array}{l}\text { Pressupõe que os conhecimentos } \\
\text { essenciais para o exercício da } \\
\text { docência são de natureza prática e, } \\
\text { portanto, não podem ser } \\
\text { ensinados, mas aprendidos tácita } \\
\text { ou reflexivamente na prática, } \\
\text { podendo evoluir com a experiência } \\
\text { e mediante interlocução com } \\
\text { professores experientes ou } \\
\text { considerando a reflexão do } \\
\text { professor sobre sua própria prática. } \\
\text { Essa concepção de aprendizagem } \\
\text { docente estabelece um } \\
\text { relacionamento entre conhecimento } \\
\text { e prática [...]. Se na primeira } \\
\text { perspectiva os professores eram } \\
\text { considerados usuários ou } \\
\text { aplicadores do conhecimento } \\
\text { acadêmico-científico, na segunda } \\
\text { são vistos como os próprios } \\
\text { designers e arquitetos da ação } \\
\text { educativa. Entretanto, esse } \\
\text { conhecimento prático que } \\
\text { produzem os professores, por estar } \\
\text { situado em contextos locais e } \\
\text { isolados, pode, com o tempo, } \\
\text { tornar-se rotineiro, naturalizado e } \\
\text { reprodutivo de relações e práticas, } \\
\text { impedindo que o professor e sua } \\
\text { docência possam se desenvolver e } \\
\text { se transformar continuamente. }\end{array}$ & $\begin{array}{l}\text { Nessa concepção, o conhecimento } \\
\text { relativo ao ensino é visto como um } \\
\text { saber que não pode ser cindido em } \\
\text { conhecimento formal (ou teórico) e } \\
\text { conhecimento prático. O } \\
\text { conhecimento que os professores } \\
\text { precisam para ensinar bem é } \\
\text { gerado quando eles consideram } \\
\text { suas próprias práticas como objeto } \\
\text { de investigação intencional, } \\
\text { considerando as teorias produzidas } \\
\text { por outros como aportes ou } \\
\text { referências que ajudam a } \\
\text { problematizar, interpretar e } \\
\text { compreender a prática de ensinar. } \\
\text { Trata-se, portanto, de um } \\
\text { conhecimento da prática, do qual } \\
\text { os professores se apropriam } \\
\text { quando geram o conhecimento } \\
\text { local "da" prática, trabalhando em } \\
\text { comunidades de investigação. } \\
\text { Assim, com essas comunidades, os } \\
\text { professores, de um lado, teorizam e } \\
\text { constroem seu trabalho, } \\
\text { conectando-o às questões sociais, } \\
\text { culturais e políticas mais amplas e, } \\
\text { de outro, desenvolvem uma postura } \\
\text { que as autoras caracterizam como } \\
\text { investigativa. }\end{array}$ \\
\hline
\end{tabular}

Fonte: Fiorentini e Crecci (2016, p. 511-512)

A partir dos estudos de Fiorentini e Crecci (2016), sistematizados no Quadro 2 sobre as 
aprendizagens dos docentes e sua relação com os conhecimentos que podem ser gerados a partir de atividades de pesquisa e, considerando-se que o GPEFCom pode ser definido como comunidade investigativa, podemos afirmar que, nesse contexto, as pesquisas dos professores da Educação Básica são geradas pelo ensino que teorizam e pela teoria que praticam. Por esse motivo, arriscamo-nos a dizer que o conhecimento gerado sobre o ensino de Matemática e sobre a formação de professores pode ser definido como conhecimento da prática.

\section{Metodologia do estudo}

Este estudo qualitativo e de cunho teórico pode ser caracterizado como documental, com inspiração em "estudos históricos", conforme apontam Fiorentini e Lorenzato (2006), considerando-se que, para levantar as informações necessárias, fizemos uso de fontes primárias, tais como: SDA, que estão configuradas na perspectiva da $\mathrm{AOE}$, dissertações, teses, fichamentos de livros e textos teóricos que tratam das seguintes temáticas: conhecimentos matemáticos trabalhados na Educação Básica e na formação de professores, no âmbito do GPEFCom.

Elegemos uma metodologia composta dos seguintes momentos e estratégias:

$\left.1^{\circ}\right)$ Análise lógica do conteúdo - consistiu em um estudo teórico sobre a história de conceitos tratados na Educação Básica.

$2^{\circ}$ ) Estudo de documentos - configurou-se a partir de leituras e análises das teses e dissertações, na perspectiva da AOE, para a Educação Básica, no âmbito do GPEFCom, sobre as temáticas: 1) Formação de professores e 2) Ensino de Álgebra, Geometria, Medidas, Número e Estatística e Tratamento da Informação.

$\left.3^{\circ}\right)$ Aprofundamento teórico sobre os conceitos de atividade, atividade de aprendizagem, atividade de pesquisa, $A O E$ e formação de professores - consistiu em um estudo sobre a teoria histórico-cultural, a teoria da atividade preconizada por Leontiev e os conhecimentos dos professores inseridos em comunidades investigativas, defendidos por Cochran-Smith e Lytle (2002).

Destacamos dois tipos de instrumentos que foram usados e possibilitaram considerar 0 movimento mais geral do estudo: 1) aqueles que contribuíram para a construção dos fatos: os textos teóricos produzidos por diversos autores e 2) as pesquisas dos professores, especialmente, as que foram configuradas na perspectiva da AOE.

Nesse contexto, a AOE se constituiu num instrumento de ensino e de pesquisa, tendo por 
meta a obtenção de dados reveladores da relação, que podem envolver a organização do ensino na sala de aula.

A análise das informações permitiu-nos organizar dois eixos temáticos que representam categorias analíticas que indicam: conhecimentos dos professores sobre o ensino de Matemática e conhecimentos dos professores sobre a formação docente.

\section{Contextualizando o GPEFCom}

O Grupo de Pesquisa Formação Compartilhada de professores - Escola e Universidade (GPEFCom), alocado na Universidade Federal de São Carlos (UFSCar), tem por objetivo principal desenvolver atividades de pesquisa que integrem os conhecimentos de pesquisadores da universidade com os conhecimentos produzidos pelos professores da Educação Básica e pelos licenciandos das diversas áreas de conhecimento. Aqui, todos os envolvidos têm oportunidade de desenvolver estudos teóricos, em nível de graduação e pós-graduação, de forma a priorizar a parceria compartilhada entre escola e universidade.

Nessa perspectiva, tanto a escola quanto a universidade são consideradas lócus privilegiados de produção e socialização de conhecimentos e de formação de professores, processo que deve se dar num ambiente acadêmico horizontal e de respeito mútuo pelos distintos saberes e práticas oriundos de cada lócus educacional. Pode-se afirmar que o GPEFCom inspirase no que Cochran-Smith e Lytle denominam de comunidade investigativa e, por esse motivo, ao frequentarem 0 grupo, todos os integrantes têm a possibilidade de assumir certa postura investigativa.

\footnotetext{
Desse modo, os professores, colaborativamente, realizam investigações, questionando o currículo existente, o modo de ensino, as práticas de avaliação e as políticas educacionais. Além disso, habilitam-se a compreender como as organizações de ensino e as lideranças escolares desafiam ou sustentam as desigualdades profundas inscritas no status quo. Destacam que a finalidade principal do construto de postura investigativa é "aprimorar a aprendizagem do aluno e as suas chances na participação e contribuição para uma sociedade diferente e democrática" [...]. (FIORENTINI e CRECCI, 2016, p. 511-512)
}

Vale a pena ressaltar que as atividades de pesquisa tiveram início no GPFCom em 2009, quando docentes da UFSCar, dos Departamentos de Física, Matemática e Metodologia de Ensino, juntamente com professores da Educação Básica que atuavam nas áreas de Física e/ou Matemática, pós-graduandos dos Programas de Pós-Graduação em Educação (PPGE) e Ensino de Ciências Exatas (PPGECE), além de licenciandos dos cursos de Física e Matemática, 
começaram a realizar pesquisas sobre as problemáticas que envolvem o ensino de Física e/ou Matemática.

Tais pesquisas foram desenvolvidas no âmbito do projeto "Produtos educacionais no Mestrado Profissional em Ensino de Física e Matemática: itinerários de desenvolvimento, implementação e avaliação, a partir da rede de pesquisa participante Escola-Universidade" (SOUSA e LEODORO, 2009), o qual integrava o programa Observatório da Educação (OBEDUC) e contava com financiamento do Instituto Nacional de Estudos e Pesquisas Educacionais Anísio Teixeira (INEP) e da Coordenação de Aperfeiçoamento de Pessoal de Nível Superior (Capes).

O projeto foi configurado a partir de dois subprojetos voltados para o ensino de Física e de Matemática. Procurou-se responder questões relacionadas: 1) ao tipo de pesquisa desenvolvida no Mestrado Profissional; 2) ao conceito de produto educacional elaborado no Mestrado Profissional; 3) à construção, pelos professores das áreas de Física e Matemática da Educação Básica, de produtos educacionais para serem utilizados em suas próprias aulas; e 4) às diferenças que podem existir entre os produtos educacionais que já estão prontos e acabados, disponíveis no mercado - os quais muitas vezes chegam às escolas de forma impositiva pelas Secretarias da Educação, na forma de livros didáticos, cadernos, materiais manipuláveis -, e aqueles produzidos coletivamente pelos próprios professores da Educação Básica.

O subprojeto da área de Matemática criou, no âmbito do OBEDUC-UFSCar, o Núcleo Interativo de Pesquisa em Ensino de Matemática (NIPEM), com o intuito de promover o "diálogo", que significa a "comunicação e redes de convivência", proposto por Bohm (2005, p. 7).

Dessa forma, no período de 2009 a 2012, os integrantes do NIPEM, que já se reuniam semanalmente, passaram então, a participar do GPEFCom. Nesse contexto, definiu-se que 0 objetivo específico do Grupo consistia em analisar e elaborar, coletivamente, produtos educacionais sob a perspectiva teórica do que Moura (2001) denomina de AOE. Tais produtos se configuram como SDA, na perspectiva da AOE, e têm formatos diversos, tais como: jogos, situações emergentes do cotidiano e história virtual do conceito (MOURA, 2001).

Nesse contexto, as atividades de pesquisa dos professores da Educação Básica consistiam em: 1) participar de disciplinas e eventos oferecidos pelos programas de pósgraduação; 2) participar das reuniões do GPEFCom; 3) participar das orientações individuais; 4) elaborar e implementar os produtos educacionais, na perspectiva da AOE, em suas aulas; 5) analisar, teoricamente, as intervenções feitas pelos professores da Educação Básica durante as aulas; 6) escrever dissertações; e 7) participar de eventos acadêmicos nacionais, com o intuito de 
apresentar e refletir sobre as pesquisas que estavam em desenvolvimento, uma vez que todos os integrantes do GPEFCom foram bolsistas, durante 12 meses, e podiam contar com verbas para diárias e passagens. Durante os 4 anos de vigência do OBEDUC-UFSCar foram desenvolvidas 8 dissertações de mestrado, conforme mostra o Quadro 3.

Quadro 3: Pesquisas desenvolvidas no subprojeto, área Matemática - OBEDUC-UFSCar

\begin{tabular}{|c|c|c|c|c|}
\hline \multicolumn{5}{|c|}{ Área: Educação Matemática } \\
\hline $\begin{array}{c}\text { Autores } \\
\text { (Ano) }\end{array}$ & Título da dissertação & $\begin{array}{l}\text { Produtos } \\
\text { educacionais } \\
\text { elaborados }\end{array}$ & Conteúdos & $\begin{array}{l}\text { Perspectivas } \\
\text { teóricas }\end{array}$ \\
\hline $\begin{array}{l}\text { Antônio do } \\
\text { Nascimento } \\
\text { Gomes (2010) }\end{array}$ & $\begin{array}{c}\text { Uma proposta de ensino } \\
\text { envolvendo geometria fractal } \\
\text { para o estudo de semelhança } \\
\text { de figuras planas }\end{array}$ & $\begin{array}{l}\text { Folhas de } \\
\text { atividades }\end{array}$ & $\begin{array}{l}\text { Geometria fractal } \\
\text { Semelhanças de } \\
\text { figuras planas }\end{array}$ & $\begin{array}{c}\text { Aulas } \\
\text { investigativas } \\
\text { (PONTE) } \\
\text { Sequências } \\
\text { didáticas }\end{array}$ \\
\hline $\begin{array}{c}\text { Angela } \\
\text { Aparecida } \\
\text { Arndt Gomide } \\
\text { Borges (2011) }\end{array}$ & $\begin{array}{l}\text { Ideias algébricas explicitadas } \\
\text { por estudantes da EJA em } \\
\text { espaços não-formais: o caso do } \\
\text { cursinho de Ribeirão Preto }\end{array}$ & $\begin{array}{l}\text { Folhas de } \\
\text { atividades }\end{array}$ & Função & $\begin{array}{l}\text { AOE (MOURA) } \\
\text { Situações } \\
\text { emergentes do } \\
\text { cotidiano }\end{array}$ \\
\hline $\begin{array}{l}\text { Cristiane } \\
\text { Maria Roque } \\
\text { Vazquez } \\
\text { (2011) }\end{array}$ & $\begin{array}{l}\text { O ensino de análise } \\
\text { combinatória no ensino médio } \\
\text { por meio de atividades } \\
\text { orientadoras em uma escola } \\
\text { estadual do interior paulista }\end{array}$ & $\begin{array}{l}\text { Folhas de } \\
\text { atividades }\end{array}$ & Análise combinatória & $\begin{array}{l}\text { AOE (MOURA) } \\
\text { Situações } \\
\text { emergentes do } \\
\text { cotidiano }\end{array}$ \\
\hline $\begin{array}{l}\text { Anderson } \\
\text { Fabrício } \\
\text { Mendes } \\
(2012)\end{array}$ & $\begin{array}{l}\text { Da resolução de quebra- } \\
\text { cabeças em sala de aula à } \\
\text { aplicabilidade no cotidiano de } \\
\text { uma marmoraria: o que os } \\
\text { estudantes do } 9 .^{\circ} \text { ano do ensino } \\
\text { fundamental falam e escrevem } \\
\text { sobre o conceito de área }\end{array}$ & $\begin{array}{l}\text { Folhas de } \\
\text { atividades e } \\
\text { quebra- } \\
\text { cabeças }\end{array}$ & Área de figuras planas & $\begin{array}{c}\text { AOE (MOURA) } \\
\text { Jogos } \\
\text { Situações } \\
\text { emergentes do } \\
\text { cotidiano }\end{array}$ \\
\hline $\begin{array}{l}\text { Maristela } \\
\text { Alves Silva } \\
\text { (2012) }\end{array}$ & $\begin{array}{c}\text { Elaborações de estudantes do } \\
7^{\circ} \text { ano do ensino fundamental } \\
\text { sobre números inteiros e suas } \\
\text { operações }\end{array}$ & Jogo & Números inteiros & $\begin{array}{l}\text { AOE (MOURA) } \\
\text { Jogos } \\
\text { Laboratório de } \\
\text { manipulação } \\
\text { virtual } \\
\text { Brincadeiras }\end{array}$ \\
\hline $\begin{array}{l}\text { Regiane de } \\
\text { Oliveira } \\
\text { Gaspar } \\
(2013)\end{array}$ & $\begin{array}{l}\text { O jogo pedagógico enquanto } \\
\text { Atividade Orientadora de Ensino } \\
\text { na iniciação algébrica de } \\
\text { estudantes de 6. } \text {. }^{\text {a }} \text { série }\end{array}$ & Jogos & Equação e variável & $\begin{array}{c}\text { AOE (MOURA) } \\
\text { Jogo }\end{array}$ \\
\hline $\begin{array}{l}\text { Marcos Hirota } \\
\text { Magalhães } \\
(2014)\end{array}$ & $\begin{array}{l}\text { Produção de sentidos e de } \\
\text { significados de estudantes do } \\
\text { ensino médio sobre o conceito } \\
\text { de volume e capacidade de }\end{array}$ & $\begin{array}{l}\text { Folhas de } \\
\text { atividades }\end{array}$ & Volume & $\begin{array}{l}\text { AOE (MOURA) } \\
\text { Situações } \\
\text { emergentes do }\end{array}$ \\
\hline
\end{tabular}




\begin{tabular}{|c|c|c|c|c|}
\hline & prismas & & & cotidiano \\
\hline $\begin{array}{c}\text { Gisele } \\
\text { Romano Paez } \\
(2014)\end{array}$ & $\begin{array}{c}\text { A produção de sentidos e } \\
\text { significados matemáticos por } \\
\text { estudantes do último ciclo do } \\
\text { ensino fundamental, por meio } \\
\text { da leitura da obra "O homem } \\
\text { que calculava" }\end{array}$ & $\begin{array}{c}\text { Fichas } \\
\text { avaliativas }\end{array}$ & $\begin{array}{c}\text { Proporção } \\
\text { Área e volumes de } \\
\text { figuras geométricas } \\
\text { Potenciação } \\
\text { Teorema de Pitágoras } \\
\text { Valor posicional } \\
\text { Base }\end{array}$ & $\begin{array}{l}\text { Histórico- } \\
\text { cultural } \\
\text { (VYGOTSKY) } \\
\text { SDA adaptadas } \\
\text { do livro } \\
\text { paradidático: O } \\
\text { homem que } \\
\text { calculava } \\
\text { (MALBA } \\
\text { TAHAN) }\end{array}$ \\
\hline
\end{tabular}

Fonte: Sousa et al. $(2017$, p. 3)

Embora o Quadro 3 não indique as iniciações científicas elaboradas pelos licenciandos do curso de Matemática e defendidas em 2010, elas também abordaram práticas de sala de aula, uma vez que os futuros professores puderam analisar, discutir, problematizar, relacionar e teorizar sobre a elaboração de produtos educacionais, ao vivenciar e, consequentemente, contribuir com sugestões para utilização de um produto educacional específico pelos professores da Educação Básica, o livro paradidático.

Em 2013, após o término do projeto e com a aprovação do Programa de Pós-Graduação Profissional em Educação (PPGPE), o GPEFCom foi ampliado e reconfigurado, uma vez que passou a acolher: 1) pós-graduandos, em nível de mestrado e doutorado, oriundos do PPGE; 2) professores da Educação Básica que cursam o Mestrado Profissional em Educação (PPGPE); 3) professores da Educação Básica; 4) licenciandos; e 5) pós-doutorandos.

Dessa forma, a partir daquele momento outras áreas, além de Matemática, passaram a fazer parte do grupo: Biologia, Educação Especial, História, Letras, Pedagogia, dentre outras. As linhas de pesquisa que passaram a conduzir o GPEFCom são: Educação Matemática, Formação de professores e Processos educativos, Linguagens, Currículo e Tecnologias.

Além das oito dissertações que foram defendidas no âmbito do OBEDUC-UFSCar, conforme mostramos no Quadro 3, no período de fevereiro de 2009 a julho de 2020 foram concluídas 26 pesquisas que não contaram com financiamento do Programa, a saber: 1 pesquisa de pós-doutorado, 4 teses de doutorado e 21 dissertações de mestrado. Desse total, apenas 3 dissertações não são da área de Matemática; logo, não têm como objeto de estudo o ensino de Matemática.

As pesquisas dos professores da Educação Básica que integram o GPEFCom tratam das seguintes temáticas: 1) sentidos e significados de licenciandos e professores em contextos de formação; 2) disciplina eletiva presente em escolas de tempo integral; 3) problematizações a partir 
de situações emergentes do cotidiano na Educação Infantil; 4) escritas de licenciandos sobre a aprendizagem da docência no contexto do PIBID; 5) saberes docentes no contexto da Educação Infantil; 6) saberes de Biologia explicitados pelos alunos do Ensino Médio no contexto escolar; 7) impressões de um grupo de professores sobre a proposta curricular de Matemática do estado de São Paulo; 8) práticas de contagem no contexto de lendas na Educação Infantil; 9) Álgebra e formação docente; 10) Atividade Orientadora de Ensino como mediação no desenvolvimento de um jogo computacional; 11) formação continuada dos professores que ensinam Matemática nas séries iniciais; 12) letramento na formação inicial de professores; 13) movimento lógico-histórico dos conceitos de fração e continuidade; 14) metanálise de teses e dissertações sobre pensamento algébrico; 15) jogos no ensino de Matemática e 16) ludicidade e Matemática na Educação Infantil, a partir dos nexos conceituais do número, conforme mostra o Quadro 4.

Quadro 4: Pesquisas desenvolvidas fora do subprojeto Matemática - OBEDUC-

UFSCar de fevereiro de 2009 a julho de 2020

\begin{tabular}{|c|c|c|c|}
\hline Autores (Ano) & Títulos & Tipo & Áreas \\
\hline $\begin{array}{l}\text { Gisele Dionísio } \\
\text { Ferreira da } \\
\text { Bertucci (2009) }\end{array}$ & $\begin{array}{l}\text { Formação continuada de professores que ensinam } \\
\text { Matemática nas séries iniciais: uma experiência em grupo }\end{array}$ & Dissertação & Matemática \\
\hline $\begin{array}{l}\text { Uaiana e Silva } \\
\text { Prates (2011) }\end{array}$ & $\begin{array}{l}\text { A atividade orientadora de ensino como mediação no } \\
\text { desenvolvimento de um jogo computacional }\end{array}$ & Dissertação & Matemática \\
\hline $\begin{array}{l}\text { Flávio de Souza } \\
\text { Pires (2012) }\end{array}$ & $\begin{array}{c}\text { Álgebra e formação docente: o que dizem os futuros } \\
\text { professores de matemática }\end{array}$ & Dissertação & Matemática \\
\hline $\begin{array}{l}\text { Cristiane } \\
\text { Vinholes } \\
\text { Jacomelli } \\
\text { (2013) }\end{array}$ & $\begin{array}{l}\text { Práticas de contagem no contexto de lendas: } \\
\text { manifestações orais de crianças de cinco anos em } \\
\text { atividades orientadoras de ensino }\end{array}$ & Dissertação & Matemática \\
\hline $\begin{array}{l}\text { Joana Cristina } \\
\text { de Souza } \\
\text { Oliveira (2013) }\end{array}$ & $\begin{array}{l}\text { Professores de matemática diante da proposta curricular } \\
\text { do estado de São Paulo (2008) }\end{array}$ & Dissertação & Matemática \\
\hline $\begin{array}{l}\text { Maria José da } \\
\text { Silva Rocha } \\
\quad(2014)\end{array}$ & $\begin{array}{l}\text { Saberes docentes: vozes de professores da infância sobre } \\
\text { Educação Matemática para crianças }\end{array}$ & Dissertação & Matemática \\
\hline $\begin{array}{l}\text { Naila Fernanda } \\
\text { Matielo } \\
\text { Cavalcante } \\
(2015)\end{array}$ & $\begin{array}{l}\text { Problematizações a partir de situaç̧ões emergentes do } \\
\text { cotidiano: compreensões e possibilidades envolvendo } \\
\text { práticas de contagem, de medida e de percepção espacial } \\
\text { em turmas de crianças de quatro anos }\end{array}$ & Dissertação & Matemática \\
\hline $\begin{array}{l}\text { Thaís Cosmo } \\
\text { (2015) }\end{array}$ & $\begin{array}{l}\text { Escritas de licenciandos em Matemática, quanto à } \\
\text { docência no contexto do PIBID }\end{array}$ & Dissertação & Matemática \\
\hline $\begin{array}{c}\text { João Paulo } \\
\text { Rezende (2015) }\end{array}$ & $\begin{array}{l}\text { Sentidos e significados manifestos por licenciandos e pós- } \\
\text { graduandos ao produzirem atividades de ensino de } \\
\text { Matemática na perspectiva lógico-histórica }\end{array}$ & Dissertação & Matemática \\
\hline
\end{tabular}




\begin{tabular}{|c|c|c|c|}
\hline $\begin{array}{l}\text { Gisele Dionísio } \\
\text { Ferreira da } \\
\text { Rocha (2015) }\end{array}$ & $\begin{array}{l}\text { Formação continuada de professores de Matemática na } \\
\text { EFAP: os significados de um grupo de professores }\end{array}$ & Dissertação & Matemática \\
\hline $\begin{array}{l}\text { Talita Secorun } \\
\text { dos Santos } \\
(2015)\end{array}$ & $\begin{array}{c}\text { Atividade Orientadora de Ensino de geometrias na } \\
\text { perspectiva lógico-histórica: unidade entre ensino e } \\
\text { aprendizagem na formação inicial de professores de } \\
\text { matemática }\end{array}$ & Tese & Matemática \\
\hline $\begin{array}{l}\text { Andréa Antunes } \\
\text { Lemo Vieira } \\
\text { (2015) }\end{array}$ & $\begin{array}{l}\text { A disciplina eletiva dos barracos às mansões: relações } \\
\text { com os saberes }\end{array}$ & Dissertação & $\begin{array}{l}\text { Matemática e } \\
\text { História }\end{array}$ \\
\hline $\begin{array}{l}\text { Victor Cherubin } \\
\text { Alves (2016) }\end{array}$ & $\begin{array}{c}\text { As relações com saberes de Biologia explicitadas pelos } \\
\text { alunos do Ensino Médio no contexto escolar: uma visão } \\
\text { sociocultural }\end{array}$ & Dissertação & Biologia \\
\hline $\begin{array}{l}\text { Everaldo } \\
\text { Gomes Leandro } \\
(2017)\end{array}$ & $\begin{array}{c}\text { O papel do grupo no processo de significação de } \\
\text { licenciandos e professores da Educação Básica sobre a } \\
\text { organização do ensino de Matemática na perspectiva } \\
\text { lógico-histórica }\end{array}$ & Dissertação & Matemática \\
\hline $\begin{array}{l}\text { Flávio de Souza } \\
\text { Pires (2017) }\end{array}$ & $\begin{array}{l}\text { Metanálise de Teses e Dissertações brasileiras em } \\
\text { Educação Matemática que tratam do pensamento } \\
\text { algébrico na organização do ensino de álgebra da } \\
\text { educação escolar básica no período de } 1994 \text { a } 2014\end{array}$ & Tese & Matemática \\
\hline $\begin{array}{l}\text { Alessandra de } \\
\text { Fátima Alves } \\
\text { (2018) }\end{array}$ & $\begin{array}{l}\text { Formação continuada em Matemática para o pedagogo } \\
\text { atuante no interior do Estado de São Paulo: sentidos } \\
\text { explicitados por professores da Educação Infantil. }\end{array}$ & Dissertação & Matemática \\
\hline $\begin{array}{l}\text { Simone Uchôas } \\
\text { Guimarães } \\
\text { (2018) }\end{array}$ & $\begin{array}{c}\text { Sentidos e significados a partir de práticas de Geometria } \\
\text { na perspectiva lógico-histórica explicitados por estudantes } \\
\text { do } 6 .^{\circ} \text { ano em situações desencadeadoras de } \\
\text { aprendizagem }\end{array}$ & Dissertação & Matemática \\
\hline $\begin{array}{l}\text { Juscelino } \\
\text { Pereira de } \\
\text { Souza (2018) }\end{array}$ & $\begin{array}{l}\text { A docência, seus saberes e a constituição do professor } \\
\text { como Profissional do ensino básico, técnico e tecnológico }\end{array}$ & Dissertação & Português \\
\hline $\begin{array}{l}\text { Fernando Luís } \\
\text { Pereira } \\
\text { Fernandes } \\
\text { (2019) }\end{array}$ & $\begin{array}{l}\text { Letramentos na formação inicial de professores que } \\
\text { ensinam Ciências e Matemática para escolas do campo }\end{array}$ & Tese & Matemática \\
\hline $\begin{array}{c}\text { Dilene } \\
\text { Aparecida } \\
\text { Amicci Mascioli } \\
\text { (2019) }\end{array}$ & $\begin{array}{l}\text { A formação em contexto na educação integral do ponto de } \\
\text { vista dos professores de uma escola pública: uma análise } \\
\text { da dialogicidade no processo educativo }\end{array}$ & Dissertação & Matemática \\
\hline $\begin{array}{l}\text { Ana Paula } \\
\text { Gladcheff } \\
\text { Munhoz (2019) }\end{array}$ & $\begin{array}{c}\text { Sistematização dos nexos conceituais fixados pelo } \\
\text { desenvolvimento lógico-histórico do conceito de fração, } \\
\text { como princípio fundamental para o ensino } \\
\text { desenvolvimental, na perspectiva da teoria histórico- } \\
\text { cultural }\end{array}$ & $\begin{array}{l}\text { Pós- } \\
\text { Doutorado }\end{array}$ & Matemática \\
\hline $\begin{array}{l}\text { Rafael Santos } \\
\quad(2019)\end{array}$ & $\begin{array}{l}\text { Um retrato dos sentidos pessoais de bolsistas egressos do } \\
\text { PIBID/Educação Especial/UFSCar a partir da escrita de }\end{array}$ & Dissertação & $\begin{array}{l}\text { Educação } \\
\text { Especial }\end{array}$ \\
\hline
\end{tabular}




\begin{tabular}{|c|c|c|c|}
\hline & portfólios & & \\
\hline $\begin{array}{c}\text { Rafael Siqueira } \\
\text { Silva (2019) }\end{array}$ & $\begin{array}{c}\text { Um estudo sobre o movimento lógico-histórico do conceito } \\
\text { de Continuidade }\end{array}$ & Tese & Matemática \\
\hline $\begin{array}{c}\text { Amanda de } \\
\text { Luca Menezes } \\
\text { Nogueira (2019) }\end{array}$ & $\begin{array}{c}\text { O jogo e o conceito de número na Educação Infantil } \\
\text { segundo os pressupostos da teoria histórico-cultural }\end{array}$ & Dissertação & Matemática \\
\hline $\begin{array}{c}\text { Gabriela } \\
\text { Guerreiro } \\
\text { Guimarães } \\
(2020)\end{array}$ & $\begin{array}{c}\text { O lúdico e a matemática na Educação Infantil: o papel das } \\
\text { interações no processo de formação de nexos conceituais } \\
\text { do número }\end{array}$ & Dissertação & Matemática \\
\hline $\begin{array}{c}\text { Ana Karina } \\
\text { Marmorato } \\
\text { Gomes (2020) }\end{array}$ & $\begin{array}{c}\text { Jogos no ensino de Matemática: um estudo de teses e } \\
\text { dissertações com a perspectiva histórico-cultural }\end{array}$ & Dissertação & Matemática \\
\hline
\end{tabular}

Fonte: Elaborado pela Autora

Nesse momento, ou seja, em outubro de 2020, estão em desenvolvimento no GPEFCom 13 pesquisas, sendo: sete teses de doutorado, que se referem às seguintes temáticas: 1) coletividade na formação continuada de professores, 2) pesquisa colaborativa e desenvolvimento profissional de professores, 3) o singular, o particular e o universal do conceito de número, 4) Programa Residência Pedagógica no IFSP, 5) Programa Residência Pedagógica na UFSCar, 6) pensamento computacional e 7) pesquisa colaborativa e desenvolvimento profissional do professor de Matemática; cinco dissertações de mestrado sobre: 1) PIBID-UFSCar, 2) uso de animações no ensino de Matemática, 3) ludicidade e Matemática na Educação Infantil, 4) trabalho coletivo na escola e 5) professor formador e o processo formativo dos professores de Educação Infantil; uma iniciação científica que trata de um estudo da geometria esférica com alunos do Ensino Médio.

\section{Análise das pesquisas desenvolvidas pelos professores da Educação Básica no GPEFCom}

Ao respondermos à pergunta deste estudo, a partir da análise das pesquisas desenvolvidas pelos integrantes do GPEFCom, pudemos constatar que, quando explicitam os conhecimentos sobre o ensino de Matemática e a formação de professores, indicam-nos que, inicialmente, mais precisamente em 2009, esses dois aspectos - ensino de Matemática e formação - estavam interligados. Podemos afirmar que se tornaram uma unidade dialética.

Naquele momento, os professores da Educação Básica que lecionavam Matemática aceitaram participar do OBEDUC-UFSCar porque sentiram necessidade de estudar os elementos 
teóricos que fundamentam a história dos conteúdos matemáticos que ministravam e as metodologias de ensino de Matemática indicadas no material de apoio que receberam da Secretaria Estadual de São Paulo, para que pudessem implementar um novo currículo que veio de fora para dentro das escolas, segundo os pressupostos de Cochran-Smith e Lytle (2002). Eles tinham consciência, segundo os estudos de Davydov (1988) apresentados anteriormente, de que não tinham alguns conhecimentos teóricos e metodológicos para desenvolver nos estudantes a atividade de aprendizagem (MOURA et al., 2010).

Sentiram necessidade e tinham motivos para repensar suas ações, conforme apontam os estudos de Leontiev. Aceitaram de imediato a proposta de analisar, elaborar e desenvolver SDA e projetos de ensino na perspectiva da AOE. Precisavam cobrir as lacunas do novo currículo. Aceitaram de imediato entrar em um grupo que se configurava como uma comunidade investigativa. Podiam desenvolver atividades de pesquisa com financiamento do governo federal, enquanto lecionavam.

Dessa forma, os objetos de estudo das pesquisas desenvolvidas no GPEFCom estão diretamente relacionados às práticas de sala de aula, conforme apontam os Quadros 3 e 4.

Há professores que analisam, por exemplo, os sentidos e significados dos sujeitos nesse caso, os alunos envolvidos nas SDA que se fundamentam na perspectiva da AOE. Sentido e significado formam uma unidade dialética. Tal unidade está presente nos processos de significação daqueles que aprendem e ensinam, do ponto de vista de Vygotsky (1991) e Goés e Cruz (2006). As análises feitas pelos professores consideram os princípios da teoria históricocultural, especialmente aqueles relacionados ao conceito de AOE, já apresentados anteriormente.

De modo geral, as pesquisas indicam ainda a preocupação dos professores em aprofundar as SDA, na perspectiva da AOE como mediação dos processos de ensino e de aprendizagem, bem como suas dificuldades para desenvolver metodologias de ensino que considerem o movimento lógico-histórico dos conceitos a serem ensinados na Educação Básica - dentre elas, as que fazem uso das novas tecnologias. Esse movimento, o lógico-histórico dos conteúdos, foi apontado por Sforni (2015) como parte integrante dos princípios didáticos e das ações docentes na perspectiva da AOE e foram descritos no Quadro 1.

Podemos afirmar que as pesquisas dos professores apresentam conhecimentos locais, tanto das escolas onde atuam, quanto do público alvo: corpo docente e alunos dessas escolas. Em cada uma dessas pesquisas há a explicitação das singularidades e particularidades das práticas escolares nas escolas. Ao mesmo tempo, chamam a atenção para que as secretarias de 
educação, municipais e estaduais, quando criarem e implementarem propostas educacionais, considerem os conhecimentos das comunidades escolares sobre currículo, ensino de Matemática, dificuldades dos alunos nos processos de ensino e aprendizagem dos conteúdos matemáticos, formação de professores etc.

Ou seja, os resultados das pesquisas dos professores indicam que se faz necessário que os governos, em âmbito municipal, estadual e federal, considerem os conhecimentos dos docentes sobre o ensino de Matemática e sobre a própria formação. Indicam que esses conhecimentos vêm de dentro da escola para fora. Nesse caso específico, o fora está relacionado à universidade. Mostram que a valorização como profissionais da Educação tem ocorrido quando participam das disciplinas oferecidas em nível de pós-graduação, uma vez que, nesses momentos, têm a oportunidade de explicitar seus conhecimentos sobre processos de ensino e de aprendizagem, currículo etc. Chamam atenção para a necessidade de que o conhecimento da prática, descrito por Cochran-Smith e Lytle (2002), seja valorizado pela sociedade brasileira.

Quando os professores estão desenvolvendo pesquisas, na perspectiva da $\mathrm{AOE}$, indicamnos que investigar as situações reais das salas de aulas sobre o ensino que ministram permite que explicitem conhecimentos relacionados à dinâmica das salas de aula, por meio das relações que fazem, à medida que analisam os processos de ensino e de aprendizagem, ou seja, praticam a teoria que estudam, uma vez que analisam, selecionam e criticam, de forma compartilhada, os textos, as atividades, os materiais didáticos que recebem, incluindo-se aí, as propostas curriculares. Podem analisar até onde é possível transpor a prática para a teoria e vice-versa. Podem questionar a teoria e buscar aquela que melhor se adéque às suas salas de aula, considerando-se suas particularidades e singularidades. Aqui, o conceito de AOE se manifesta.

Nesse contexto, os professores estão desenvolvendo o que Cochran-Smith e Lytle (2002) denominam de "conhecimento da prática". Assim,

concordamos com Cochran-Smith e Lytle (2002) que as problemáticas levam às perguntas interessantes que passam a conduzir as pesquisas dos professores. Por este motivo, as questões não são triviais e estão relacionadas às suas experiências cotidianas [...]. As perguntas que Gomes (2010), Borges (2011), Silva (2012), Paez (2012) e Mendes (2012) explicitaram em suas dissertações são: Como se dá o processo de elaboração, aplicação, análise e recepção pelos estudantes de um material didático envolvendo Geometria fractal para o aprendizado do conceito de semelhança de figuras na $8^{a}$ série do Ensino Fundamental? (GOMES, 2010, p. 17) Quais são as ideias algébricas explicitadas por estudantes de EJA quando vivenciam, em um espaço não formal, situações-problema? (BORGES, 2011, p. 6). Quais elaborações os estudantes manifestam e/ou explicitam enquanto vivenciam as atividades orientadoras de ensino com números inteiros? (SILVA, 2012, p. 6). Quais são os sentidos e significados matemáticos que podem ser produzidos por estudantes do $8^{\circ}$ e $9^{\circ}$ anos do Ensino Fundamental, de uma escola pública estadual da cidade de 
[Nome do Município], interior do Estado de São Paulo, a partir da leitura das estórias do livro "O Homem que Calculava"? (PAEZ, 2012, p. 7). 0 que estudantes do $9^{\circ}$ ano do Ensino Fundamental falam e escrevem sobre o conceito de área enquanto vivenciam atividades orientadoras de ensino, tanto na sala de aula, quanto no contexto de uma marmoraria? (MENDES, 2012, p. 10). (SOUZA, 2014, p. 927)

Dessa forma, a partir das questões que geram os problemas de pesquisa, as ações sistematizadas nas dissertações, nas teses e nas iniciações científicas dos integrantes do GPEFCom articulam-se em torno do compromisso da formação continuada de professores que prevê a intervenção na realidade educacional, mediante pesquisas que tratam da prática e da sistematização dos conhecimentos educacionais que estão postos.

Uma das ações está relacionada à criação, à elaboração e ao desenvolvimento de produtos educacionais em sala de aula. $O$ conhecimento dos professores sobre a produção de produtos educacionais que povoam o ensino de Matemática tem mostrado que materiais didáticos, SDA nos formatos de jogos diversos, situações emergentes do cotidiano e história virtual do conceito, bem como fichas avaliativas só fazem sentido em suas práticas, se forem pensados coletivamente.

A maioria desses produtos contém SDA que se fundamentam na perspectiva da AOE e considera as particularidades e singularidades de cada uma das salas de aula. É por esse motivo que enfatizam que não basta apenas um professor escolher uma SDA e tentar reproduzi-la em sua escola, sem preocupar-se com o contexto em que ela foi elaborada e desenvolvida. Dependendo das características dos alunos, as SDA precisam ser remodeladas. Tal remodelação ou adequação faz parte da atividade dos professores. Para que ela se efetive, os professores precisam conhecer, com certo aprofundamento, o ensino que ministram.

\footnotetext{
Podemos inferir que os conhecimentos que os professores produzem sobre o ensino de matemática estão relacionados: aos conhecimentos das dificuldades deles e dos estudantes, quando a temática envolve os processos de ensino e de aprendizagem; à elaboração e organização de atividades que possam atender as expectativas dos estudantes; aos sentimentos dos estudantes em relação às aulas de matemática, e conhecimentos relacionados ao uso de sínteses históricas, documentos oficiais e materiais disponibilizados para o ensino. (SOUSA, 2014, p. 934)
}

Há de se considerar ainda que as pesquisas dos professores que participam do GPEFCom nos trazem conhecimentos sobre o ensino de números, álgebra, análise combinatória, continuidade, fração, geometria euclidiana e geometrias não euclidianas, a partir de nexos conceituais que podem ser desenvolvidos na Educação Básica, a partir de SDA. Esses nexos conceituais (externos e internos) fazem parte do movimento lógico-histórico dos conceitos matemáticos. São delineados a partir das historiografias da Matemática. 
Quando o foco está mais especificamente na formação e na prática docente, os conhecimentos decorrentes das pesquisas dos professores estão relacionados: 1) aos saberes docentes; 2) ao desenvolvimento profissional dos professores; 3) à necessidade de constituir grupos colaborativos com ênfase na coletividade das escolas; 4) à necessidade de desenvolver um trabalho interdisciplinar na Educação Básica; 5) à importância da participação dos professores nas elaborações e implementações curriculares; 6) aos desafios da educação integral e das disciplinas denominadas de eletivas; 7) ao papel da escrita durante o processo de formação inicial e continuada; e 8) aos desafios que se apresentam nos programas institucionais, quando se analisam as relações entre iniciação à docência e formação continuada.

Dessa forma, os conhecimentos relacionados à temática da formação e da prática docente indicam a necessidade de investir em atividades de pesquisas que possam ser consideradas, propostas de formação continuada de professores a partir da incorporação dos estudos sobre a formação crítica e reflexiva e a ação investigativa, rompendo, assim, com um tipo de formação continuada fundamentada na racionalidade técnica, a qual prioriza apenas os conteúdos das diversas áreas do conhecimento, especialmente aqueles produzidos nas universidades.

Por último, gostaríamos de enfatizar que os conhecimentos que se apresentam nas pesquisas dos professores indicam que se faz necessário que os conhecimentos dos professores que estão em prática e envolvidos com atividades de pesquisa em uma comunidade investigativa - nesse caso, o GPEFCom -, quando sistematizados e analisados nos formatos de dissertações, teses, iniciações científicas, artigos e relatos de experiências, sejam considerados conhecimentos teóricos, uma vez que a análise dos dados está fundamentada, teoricamente, nos pressupostos da teoria histórico-cultural, com ênfase nos conceitos de atividade, atividade de aprendizagem, SDA e AOE.

\section{Considerações Finais}

Ao nos apropriarmos dos conhecimentos sobre o ensino de Matemática e a formação de professores, a partir da análise das pesquisas de professores de Matemática da Educação Básica, integrantes do GPEFCom, constatamos que as atividades de pesquisas promovidas tanto pela pós-graduação quanto pelo grupo levam em conta a valorização da coletividade na formação de professores.

Os conhecimentos teóricos descritos nas pesquisas dos professores tratam: 1) dos conceitos matemáticos que ensinam; 2) dos fundamentos teóricos e metodológicos que se 
apresentam em suas práticas escolares; 3) dos currículos que ministram; 4) das dificuldades dos alunos ao aprender Matemática e 5) das dificuldades que possuem ao ensinar Matemática. Ou seja, nesse contexto, as pesquisas dos professores da Educação Básica não estão dissociadas dos conhecimentos da prática e não desprezam a teoria. Há, aqui, uma unidade dialética em constante movimento, formada pelos conhecimentos das práticas e dos conhecimentos teóricos.

No entanto, faz-se necessário chamar atenção para o fato de que tais conhecimentos são provenientes do compartilhamento de ideias e ações de diferentes sujeitos e em diferentes momentos de formação.

Ademais, um papel de extrema importância cabe ao GPEFCom, uma vez que o Grupo tem permitido a efetivação de um ambiente de diálogo tão necessário em razão da complexidade dos problemas a serem enfrentados no contexto educacional. O resultado é a formação de professores capazes de ampliar os horizontes da escola, superar o isolamento profissional e reconhecer a criatividade - aspectos essenciais para o trabalho docente, a partir da atividade de pesquisa.

O contexto de desenvolvimento das ações do GPEFCom revela um cenário privilegiado de formação de professores e pesquisadores, cujo fundamento se instaura na coletividade e no compartilhamento objetivados na melhoria da prática educacional. Consequentemente, os conhecimentos teóricos sobre o ensino de Matemática e a formação dos professores se manifestam, continuamente.

Nesse contexto, o conjunto de pesquisas já desenvolvidas e em desenvolvimento mostra um modo particular de organização do trabalho coletivo, cujas diferentes perspectivas se voltam para a compreensão e a transformação de práticas educacionais. É por esse motivo que podemos assumir o Grupo como comunidade investigativa. As pesquisas dos professores ilustram a postura investigativa que está em movimento. Ajudam-nos a compreender como os conhecimentos dos professores sobre o ensino de Matemática e a formação de professores só fazem sentido, se forem constituídos coletivamente.

\section{Referências}

BOHM, David. Diálogo-comunicação e redes de convivência. São Paulo: Palas Athena, 2005.

BRASIL. Ministério da Educação. Instituto Nacional de Estudos e Pesquisas Educacionais Anísio Teixeira. Estatísticas dos professores no Brasil. Brasília: MEC/INEP, 2003.

CARAÇA, Bento de Jesus. Conceitos fundamentais da Matemática. 2. ed. Lisboa: Gradiva, 1998. 
COCHRAN-SMITH, Marilyn; LYTLE, Susan L. Dentro/fuera: enseñantes que investigan. Tradución de Virginia Ferrer. Madrid: Akal, 2002.

DAVIDOV, Vasili Vasilovich; MARKOVA, Aelita Kapitónovna. La concepcion de la actividad de estudio de los escolares. In: DAVIDOV, Vasili Vasilovich; SHUARE, Marta. La psicología evolutiva y pedagogía en la URSS: antología. Tradución de Marta Shuare. Moscú: Editorial Progreso, 1987, p. $316-336$.

DAVYDOV, Vasili Vasilovich. La enseñanza escolar y el desarrollo psiquico: investigación psicológica teórica y experimental. Tradución de Marta Shuare. Moscu: Editorial Progreso, 1988.

DINIZ-PEREIRA, Júlio Emílio; ZEICHNER, Kenneth M. (Org.). A pesquisa na formação e no trabalho docente. 2. ed. Belo Horizonte: Autêntica, 2011.

FIORENTINI, Dario; CRECCI, Vanessa. Interlocuções com Marilyn Cochran-Smith sobre aprendizagem e pesquisa do professor em comunidades investigativas. Revista Brasileira de Educação, Rio de Janeiro, v. 21, n. 65, p. 505-524, abr./jun. 2016.

FIORENTINI, Dario; LORENZATO, Sergio. Investigação em Educação Matemática: percursos teóricos e metodológicos. Campinas: Autores Associados, 2006.

GÓES, Maria Cecília Rafael; CRUZ, Maria Nazaré da. Sentido, significado e conceito: notas sobre as contribuições de Lev Vigotski. Pro-Posições, Campinas, v. 17, n. 2, p. 31-45, maio/ago. 2006.

MOURA, Anna Regina Lanner de; MACIEL, Domício Magalhães; CATALANI, Érica; FIOREZI, Fabiana; MELO, Gilberto Francisco Alves de; SOUSA, Maria do Carmo de; MISKULIN, Rosana Seguerra; MACHADO, Rosa Maria. Movimento conceitual em sala de aula. In: CONFERÊNCIA INTERAMERICANA DE EDUCAÇÃO MATEMÁTICA, 11, 2003, Blumenau. Anais da XI CIAEM. Blumenau: 2003, p. 1-15.

MOURA, Manoel Oriosvaldo de. A atividade de ensino como ação formadora. In: CASTRO, Amélia Domingues de; CARVALHO, Anna Maria Pessoa de. (Org.). Ensinar a ensinar: didática para a escola fundamental e média. São Paulo: Pioneira Thomson Learning, 2001, p. 143-162.

MOURA, Manoel Oriosvaldo de.; ARAUJO, Elaine Sampaio; RIBEIRO, Flavia Dias; PANOSSIAN, Maria Lucia; MORETTI, Vanessa Dias. A atividade orientadora de ensino como unidade entre ensino e aprendizagem. In: MOURA, Manoel Oriosvaldo de. (Org.). A atividade pedagógica na teoria histórico-cultural. Brasília: Liber Livro, 2010, p. 81-109.

ROSA, Josélia Euzébio da; MORAES, Silia Pereira Gonzaga de; CEDRO, Wellington Lima. As particularidades do pensamento empírico e do pensamento teórico na organização do ensino. In MOURA, Manoel Oriosvaldo de. (Org). A atividade pedagógica na teoria histórico-cultural. São Paulo: Liber, 2010, p. 67-80.

ROSA, Josélia Euzébio da; MORAES, Silvia Pereira Gonzaga de; CEDRO, Wellington Lima. As particularidades do pensamento empírico e do pensamento teórico na organização de ensino. In: MOURA, Manoel Oriosvaldo de. (Org.). A atividade pedagógica na teoria histórico-cultural. São Paulo: Liber, 2010, p. 67-76.

SFORNI, Marta Sueli de Faria. Interação entre Didática e Teoria Histórico-Cultural. Educação \& Realidade, Porto Alegre, v. 40, n. 2, p. 375-397, abr./jun. 2015. 
SOUSA, Maria do Carmo de. Quando professores que ensinam Matemática estão em atividades de pesquisa. Ciência \& Educação, Bauru, v. 20, n. 4, p. 917-935, out./dez. 2014.

SOUSA, Maria do Carmo de; LEODORO, Marcos Pires. Projeto de pesquisa Produtos educacionais no Mestrado Profissional em Ensino de Física e Matemática: itinerários de desenvolvimento, implementação e avaliação, a partir da rede de pesquisa participante EscolaUniversidade. São Carlos: UFSCar, 2009.

SOUSA, Maria do Carmo de; TEDESCHI, Wania; SILVA, Miguel Jocélio Alves; SILVA, Rafael Siqueira; LEANDRO, Everaldo Gomes; FERNANDES, Fernando Luís Pereira; GUIMARAES, Simone Uchôas; NAVARRO, Eloisa Rosotti. Nas trilhas da perspectiva histórico-cultural: caminhos do grupo de pesquisa "Formação Compartilhada de Professores - Escola e Universidade". In: Fórum de Discussão: Parâmetros Balizadores da Pesquisa em Educação Matemática no Brasil, 4 , 2017, São Carlos. Anais do IV FDPBPEMB. São Carlos: UFSCar, 2017.

VYGOTSKY, Lev Semyonovich. A formação social da mente. Tradução de José Cipolla Neto, Luís Silveira Menna Barreto, Solange Castro Afeche. São Paulo: Martins Fontes, 1991. 